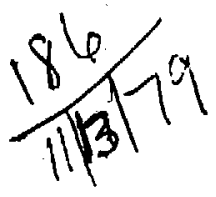

DR. 290

\title{
MASTER
}

\section{TRITIUM CONTAINMENT COSTS AT LAWRENCE LIVERMORE LABORATORY}

\author{
J. F. Shaw \\ R. M. Alire
}

June 15,1979

Work performed under the auspices of the U.S. Department of Energy by the UCLLL under contract number W-7405-ENG-48.

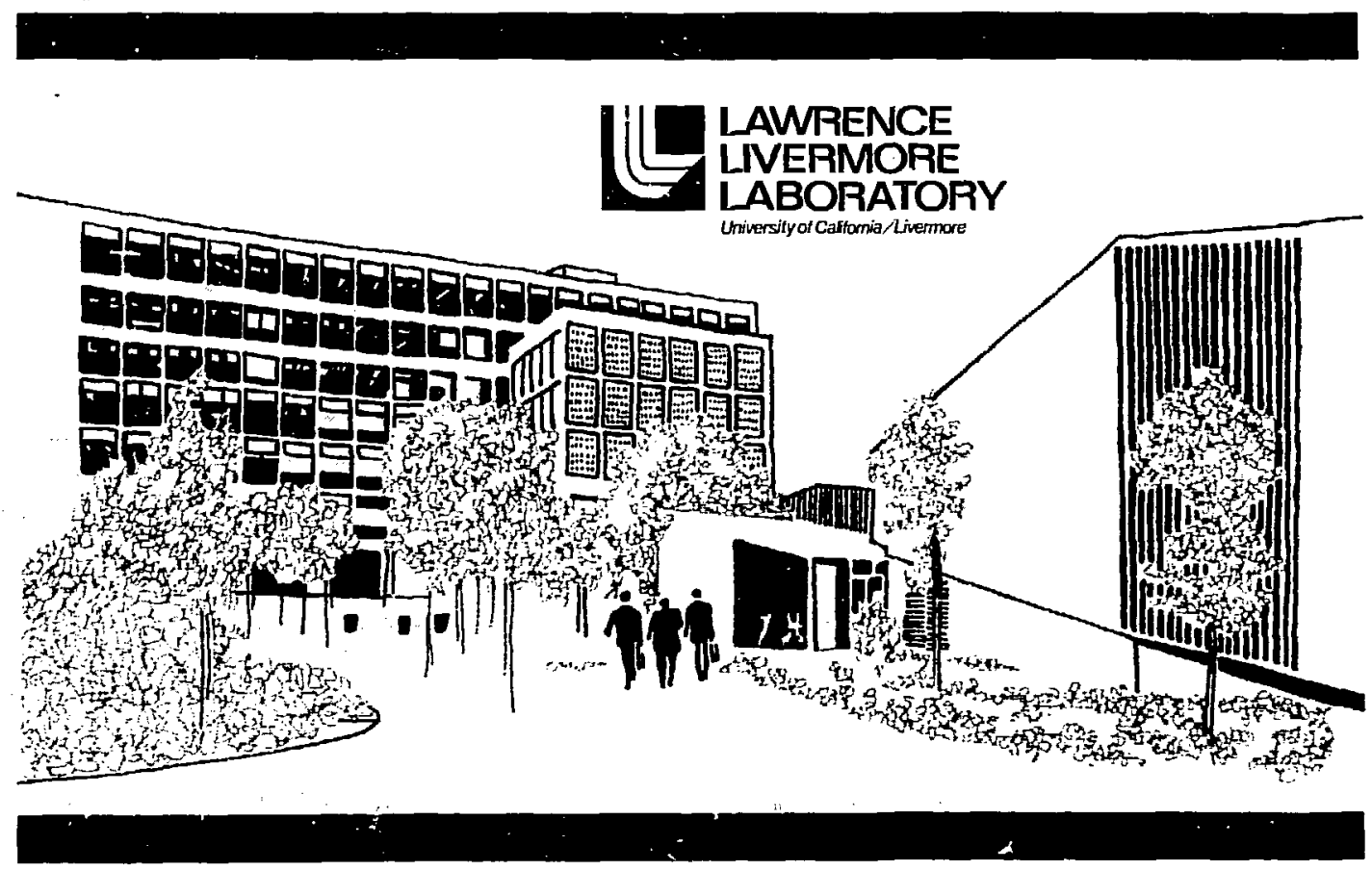




\title{
近 \\ LAWRENCE LVERMORE LABORATORY
}

University of Caftornia, Livermore, Califomia, 94550

\author{
UCRL-52795
}

\section{TRITIUM CONTAINMENT COSTS AT LAWRENCE LIVERMORE LABORATORY}

\author{
J. F. Shaw \\ R. M. Alire
}

Manuscript date: June 15, 1979

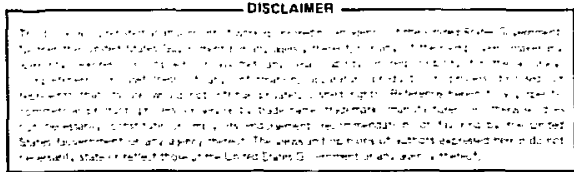




\section{CONTENTS}

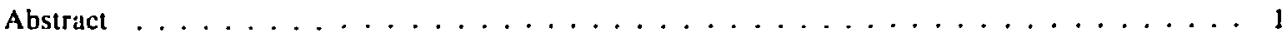

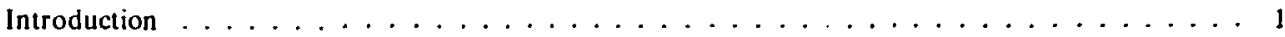

Biological Hazard of Tritium and Tritiated Water ................

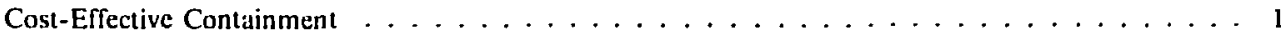

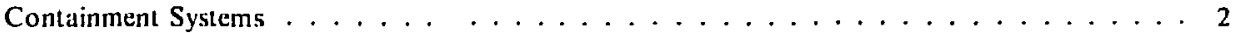

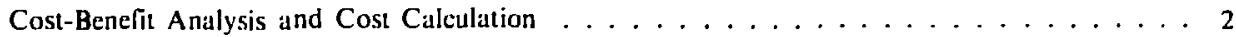

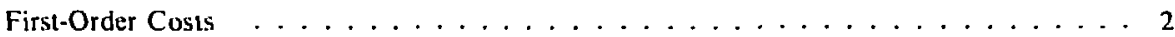

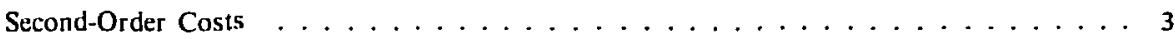

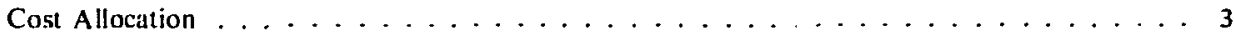

Levels of Containment $\ldots \ldots \ldots \ldots \ldots \ldots \ldots \ldots$

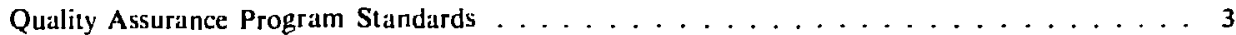

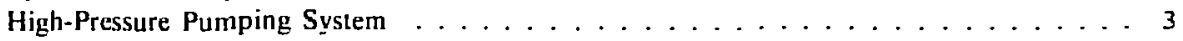

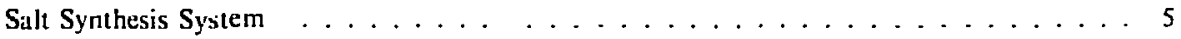

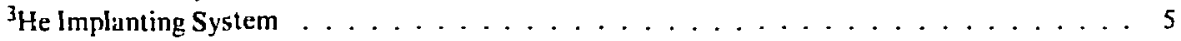

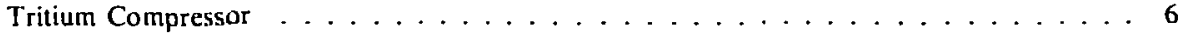

Cryogenic Studies Systems . . . . . . . . . . . . . . . . . 6

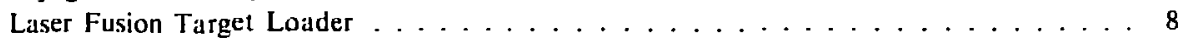

Cost-Saving Construction Techniques $\ldots \ldots \ldots \ldots \ldots$

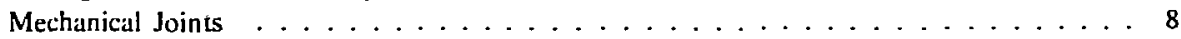

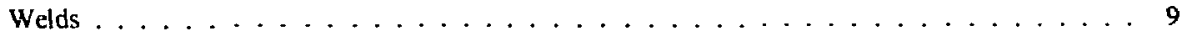

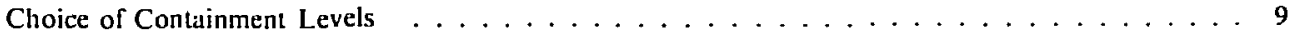

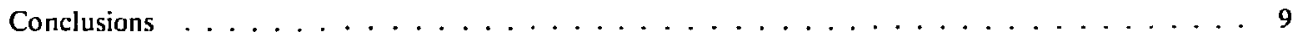

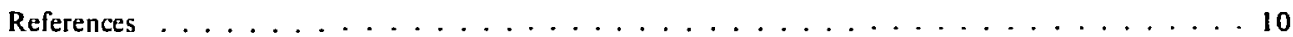




\section{TRITIUM CONTAINMENT COSTS AT LAWRENCE LIVERMORE LABORATORY}

\section{ABSTRACT}

Lawrence Livermore Laboratory has improved tritium-handing systems to pre- ent significant releases of tritium to the environment. Two methods of lowering the costs of such systems have been found: maintaining design flexibility and combining the best features of single- and double-containment designs.

\section{INTRODUCTION}

For the past eight years, we at Lawrence Livermore Laboratory (LLL) have improved tritiumhandling systems to reduce releases of tritium to the environment. This paper discusses the concept of cost-effective containment, and it compares the costs of present systems with those of a system that releases tritium at a level no greater than the natural abundance of tritium - the only standard currently available. From experience acquired during these years, we have developed a system that minimizes tritium release and is cost-effect ive. ${ }^{!}$

Our earliest approach was to build singlecontainment systerns using state-of-the-art matetials and precision fabricating techniques. Later, we investigated less costly containment strategies such as double-containment systems, in which savings were realized by using cheaper materials and less demanding construction methods. This approach was no panacea, however, since double containment is undesirable for some systems. When possible, our final practice has been to combine the two desigus by using single containment in some sections and double containment in others.

\section{BIOLOGICAL HAZARD OF TRITIUM AND TRITIATED WATER}

Tritium is a radioactive ${ }^{2}$ isotope of hydrogen that decalys by beta emission to form ${ }^{3} \mathrm{He}$; the maximum energy of the beta particle is $18 \mathrm{keV}$, and the average is $5.7 \mathrm{keV}$. It is generally accepted that diatomic tritium $\left(T_{2}\right)$ presents no significant radiation hazard because these molecules do not penetrate the skin and are poorly absorbed and retained by the body. ${ }^{3}$ The biological half-life is about eight days.

Beta radiation initiates reaction between tritium and oxygen in the atmosphere to form tritiated watert: the conversion rate is $1 \%$, day. Tritium oxides ( $\mathrm{T}, \mathrm{O}, \mathrm{TDO}$, and $\mathrm{THO}$ ) do present at biological hazard because they rapidly enter the body through the skin and lungs. ${ }^{5}$ The lethal dose is $15 \mathrm{Ci}$ (total body burden). The maximum permissible concentration of tritium oxide is 400 times less than that of tritium.

\section{COST-EFFECTIVE CONTAINMENT}

The concept of cost-effective containment must be based on practical rather than arbitrary goals and must apply to all orders of containment. For an inert-gas system, for example, a cost-effective containment system must meet well-established pressure safety codes, but need not exceed them; a first-order containment system-defined as one that meets experimental needs and complies with pressure safety codes-is adequate. Because of the biological hazard of tritjum, however, safety considerations require that tritium-containing systems use second-order containment, which may involve additional strengthening or encapsulation of the primary container. 


\section{CONTAINMENT SYSTEMS}

The Tritium Facility is devoted to research, development, and engineering on tritium-related problems, e.g., laser fusion targets. magnetic fusion energy (MFE) reactors, nuclear devices, and tritium-property studies. In this work, two types of systems are used to transfer accurately measured quantities of tritium into experimental apparatus.

The first system is used to process relatively pure tritium; gas remaining after completion of the experiment is normally reprocessed at another site. In the second system, small amounts of tritium are added to an inert carrier gas (e.g., argon); after the experiment, the tritium is removed before the carrier gas is recycled or vented to the atmosphere. Hybrid systems incorporate features of both systems.

These systems can be further classified by their operating pressure range, e.g., from vacuum to $200 \mathrm{kPa}$ and from vacuum to over $200 \mathrm{MPa}$. Higher pressures obviously require stronger materials and more rigorous construction techniques.

\section{COST-BENEFIT ANALYSIS AND COST CALCULATION}

Sherwood' calculated a cost-benefit of $\mathbf{\$ 2 . 5 0}$ for every $\mathrm{Ci}$ of radiation not released to the environment, based on the assumption that increasing the illness and death rate of the population would decrease productivity. In his calculations, Sherwood assigned $\mathbf{\$ 1}$ million for the loss of a human life. Cohen and Higgens ${ }^{6}$ estimated a cost benefit of $\$ 0.10$ per $\mathrm{Ci}$ not released, based on a value of $\$ 240,000 /$ life lost. The difference between the two estimates results from using different proportionality constants to describe dilution of radiation in the biosphere; Cohen and Higgens used $7.2 \times$ $10^{-16}$ and Sherwood used $1 \times 10^{-14}$.

Sherwood next estimated the cost of secondorder containment (including materials, fabrication, installation, maintenance, debt service, depreciation, and allowances for $6 \%$ inflation) and concluded that $\$ 20 / \mathrm{Ci} / \mathrm{y}$ (in 1978 dollars) was a reasonable cost. This value was a maximum based on the assumption that tritium is released continuously from the first-order containment system; if there is no release, then the cost for a secondorder system is zero. He derived the following rela- tion for reasonable investment (C), using $\$ 20 / \mathrm{Ci} / \mathrm{y}$ as the cost-benefit value:

$$
\mathrm{C}=20 \mathrm{PR} \text {. }
$$

where $P$ is the probability of tritium release per year caused by first-order system failure and $R$ is the probable amount of radiation released. For example, for a system containing $100 \mathrm{~g}$ of $\mathrm{T}_{2}\left(10^{6} \mathrm{Ci}\right)$ that has a probability of one failure (in which the entire $T_{2}$ inventory is released) in ten years, the investment is $C=20\left(10^{-1}\right)\left(10^{6}\right)=\$ 2 \times 10^{6}$. The validity of $P$ is based on the history of releases from first-order containment systems at the Tritium Facility.

It is important to note that $\mathbf{C}$ decreases with decreasing release probability, which can lead to speculation that second-order containment costs can be eliminated completely by designing firstorder systems with release probabilities of zero. Such thinking inevitably leads to "overkill" and unacceptably high first-order containment costs.

\section{First-Order Costs}

The cost of a first-order containment system can be kept within prescribed limits if the system is designed to meet only experimental or process needs and to satisfy compressed-gas safety codes. (Although the second-order system deals only with tritium, for simplicity we refer to the first-order system in the following example as a tritiumhandling system.)

A containment system designed to make equilibrium transfers from one vessel to another is the most elementary and least expensive type of tritium-handling systems. $A$ basic system to contain $100 \mathrm{~g}$ of $\mathrm{T}_{2}$ would consist of 20 valves, 20 connecting lines, and at least one pressure-sensing transducer and its supporting electronics. In 1978 dollars, materials costs would be $\$ 13,000$, labor costs would add $\$ 39,000$, and engineering, scientific, and administrative expenses would bring the total to nearly $\$ 100,000$, or $\$ 0.10 / \mathrm{Ci}$.

Unfortunately, once the pressures in the vessels reach equilibrium, nothing more can be done, and removal of vessels would release appreciable amounts of tritium. Making the system useful for experimental work requires more valves and transducers, uranium traps (which require electric power and heating controls), circulation pumps, 
vacuum pumps, pressure-reduction tanks, inert-gas inlets, fume hoods, a furnace, and a bracket support system. Such additional apparatus can increase the cost to as much as $\$ 1.80 / \mathrm{Ci}$. Furthermore, this estimate does not, of course, include the cost of auxiliary equipment needed for experimental purposes since such items are not part of the containment system.

\section{Second-Order Costs}

The additional cost of a second-order system that can be justified on a cost-benefit basis is derived by assigning a failure probability to the system, calculating the total cost of the system (Eq. 1), and subtracting the cost of the first-order system. For example, the system described above that handles $100 \mathrm{~g}$ of $\mathrm{T}_{2}$ costs $\$ 2.00 / \mathrm{Ci}$. If the firstorder cost is $\$ 1.80 / \mathrm{Ci}$, the second-order costs would be $\$ 0.20 / \mathrm{Ci}$ (or $\$ 200,000$ for the system).

\section{COST ALLOCATION}

The costs of equipment and tritium containment systems are often difficult to categorize as strictly experimental or safety expenses; there is considerable overlap in most cases. For example, a pressure-sensing transducer is important both for experimental work and for containment, and assigning the proportional cost to each purpose is a matter of judgment; the secondary container of the transducer is, of course, entirely a second-order cost. Or, in the case in which two valves and a connecting tube are sufficient for the experiment, safety may require extra valves, which are clearly considered second-order costs; if, however, welding techniques more exacting than those needed for first-order containment are required for the entire system, the allocation of costs becomes more complicated.

\section{LEVELS OF CON:TAINMENT}

A single-containment system relies on the process lines, experiment-vessel walls, and valve bodies to provide containment; tritium cannot be captured if the system integrity is breached. Assurance against breakage is provided by careful control of materials (e.g., state-of-the-art alloys) and fabrication techniques, but this can be expensive and exceed the cost-effective limit of $\$ 2.00 / \mathrm{Ci}$.
A double-containment system relies on a second line of defense against equipment failure. The process lires, experiment vessels, and valve bodies are made from less cosily materials using less rigorous construction techniques and are placed within a second container. Secondary containment has been used industrially for many years, e.g., the double hull of the Titanic. The second container provides an effective backup in case of failure, but it neither substitutes for sound design and construction of the primary system nor replaces good operating practices-witness the fate of the Titanic.

\section{QUALITY ASSURANCE PROGRAM STANDARDS}

The LLL Tritium Facility initiated a Quality Assurance (QA) program in 1972 to reduce the probability of tritium release. (This program should not be confused with the laboratory-wide QA program instituted in 1978; the Tritium Facility QA program was recently rewritten to conform to the later LLL program and currently includes a limitation on system costs.) Essentially, the program established standards for construction techniques, materials, documentation, and Operational Safety Procedures. The program requires using highquality materials and demands excellence in fabrication but does not provide details.

\section{High-Pressure Pumping System}

The first system built under the QA program was the high-pressure pumping system, which hardles a large tritium inventory. Care was taken in its design to make it cost-effective. This system provides up to $60 \mathrm{~g}$ of tritium at a maximum pressure of $103 \mathrm{MPa}$. With the exception of the compressor, it is a single-containment system consisting of a 34-MPa diaphragm compressor that discharges into a high-pressure manifold; the manifold has connecting ports, pressure-sensing transducers, adjoining low-pressure manifolds, and flush-gas retention tanks (Fig. l). To protect the primary system against overpressure and loss of tritium in case of failure of the highly stressed transducers, the system is connected to back-up tanks by bursting disks.

The system was made from ultrasonically inspected 316 VIM/VAR stainless steel stock. All welds conformed to the specilications given in the ASME Boiler and Pressure Vessel Code (Section 


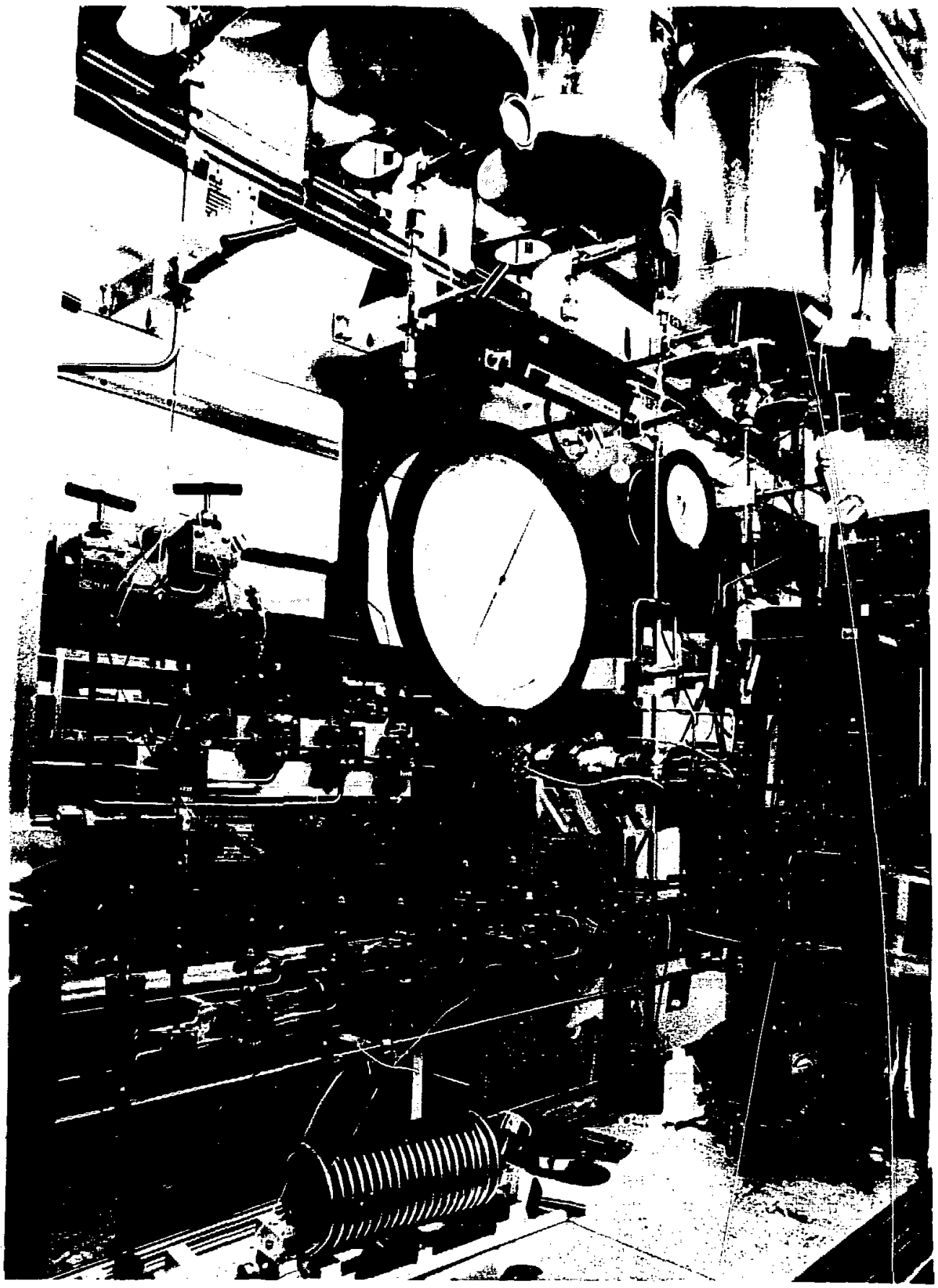

FIG. 1. High-pressure pumping system. This system provides up to $60 \mathrm{~g}$ of tritium at a maximum pressure of $103 \mathrm{MPg}$. 
IX, 1971); welds were checked by radiography and dye penetration. The cost, including modifications of an existing compressor, was $\$ 1.12$ million. This cost was somewhat high because the expense of preliminary materials studies was not amortized over subsequently built systems that benefited from these studies. Because of the tremendous tritium inventory potential of the system $\left(6 \times 10^{5} \mathrm{Ci}\right)$, the cost per Curie is low. (The working inventory, however, is somewhat lower-about $4 \times 10^{5} \mathrm{Ci}$.)

\section{Salt Synthesis System}

The salt synthesis system is another singlecontainment system. Low-pressure tritium gas (100 kPa) from product tanks is passed through uranium traps that remove ${ }^{3} \mathrm{He}$ and is fed into a reactor (Fig. 2). For added security, the system uses beliows-sealed flow valves, in which a packing gland backs up the bellows. In accordance with $Q A$ guidelines, the multitude of necessary valves and connecting lines were made from ultrasonically inspected 316 VIM/VAR stock, and welds on the primary system met the specifications of the ASME Builer and Pressure Vessel Code (Section IX, 1971). To reduce costs, Iadiographic inspection of the welds was waived and the secondary-system manifolds serving the valve bonnets were assembled using single-pass fusion welds. Hook-up lines connecting the secondary system manifolds to the valve bonnets were copper with brazed joints.

\section{${ }^{3}$ He Implanting System}

The implanting system interstitially implants ${ }^{3} \mathrm{He}$ in metals and is a single-containment system. It

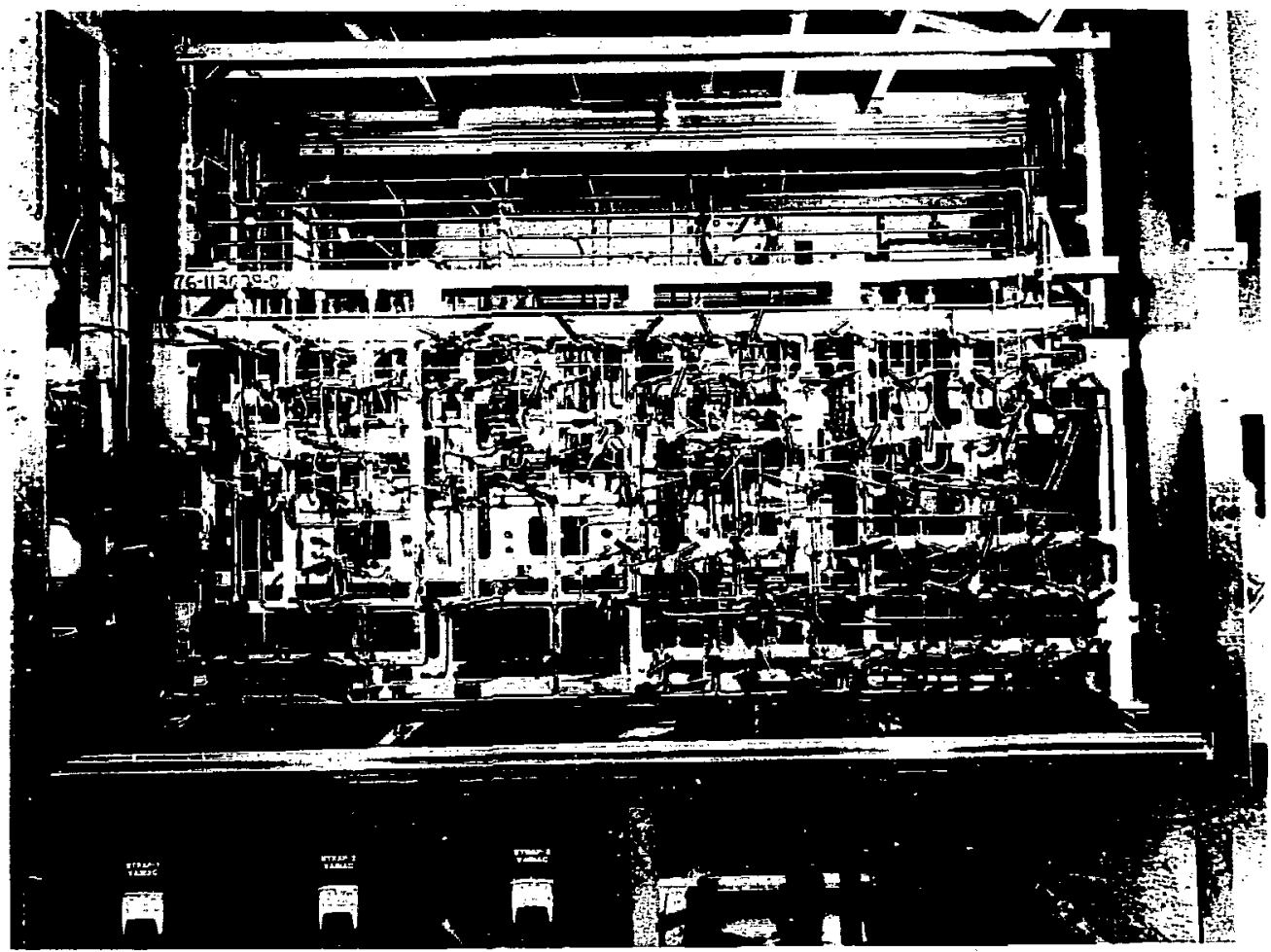

FIG. 2. Salt synthesis system. Low-pressure tritium gas $(100 \mathrm{kPa})$ from product tanks is passed through uranium traps that remove ${ }^{3}$ He and is fed into a reactor. 
consists of two parts (Fig. 3): a low-pressure circulation and recovery section of welded construction (single-pass TIG) and a high-pressure section for introducing gases into the reaction chamber, which is assembled using mechanical joints.

\section{Tritium Compressor}

Secondary containment was the only solution for protecting the high-pressure pumping-system compressor, a PPI model $1-Q$ diaphragm compressor rated at $34 \mathrm{MPa}$ (Fig. 4). The machine could not be upgraded to the standards of Tritium Facility QA Plan M 078-01 since the numerous internal working parts required complex manufacturing processes to duplicate. Because of the compressor's substantial size and weight and large tritium inventory, it proved simplest to enclose the entire compressor in a heavy-walled steel container of welded construction.

\section{Cryogenic Studies Systems}

The systems for cryogenic studies are good examples of cost-effectiveness achieved using secondary containment. ${ }^{7}$ Although these systems work at low pressures and handle small volumes of tritium, the system inventory is larger than indicated by the volume; the density of solid tritium is $\sim 0.3 \mathrm{~g} / \mathrm{cm}^{3}$ and that of tritium gas at $300 \mathrm{MPa}$ and $293 \mathrm{~K}$ is $\sim 0.2 \mathrm{~g} / \mathrm{cm}^{3}$.

In one case, a small-diameter pipe serves as a secondary container for an electrical-conductivity measuring cell. The pipe section was cut from a length of commercially available pipe; the cut ends were trimmed, and closures made from commercially a vailable flanges were welded onio both ends. A second example is the ir spectrometer. Though the cryogenic cell is small, the bulkiness of the specIrometer required that the entire apparatus be

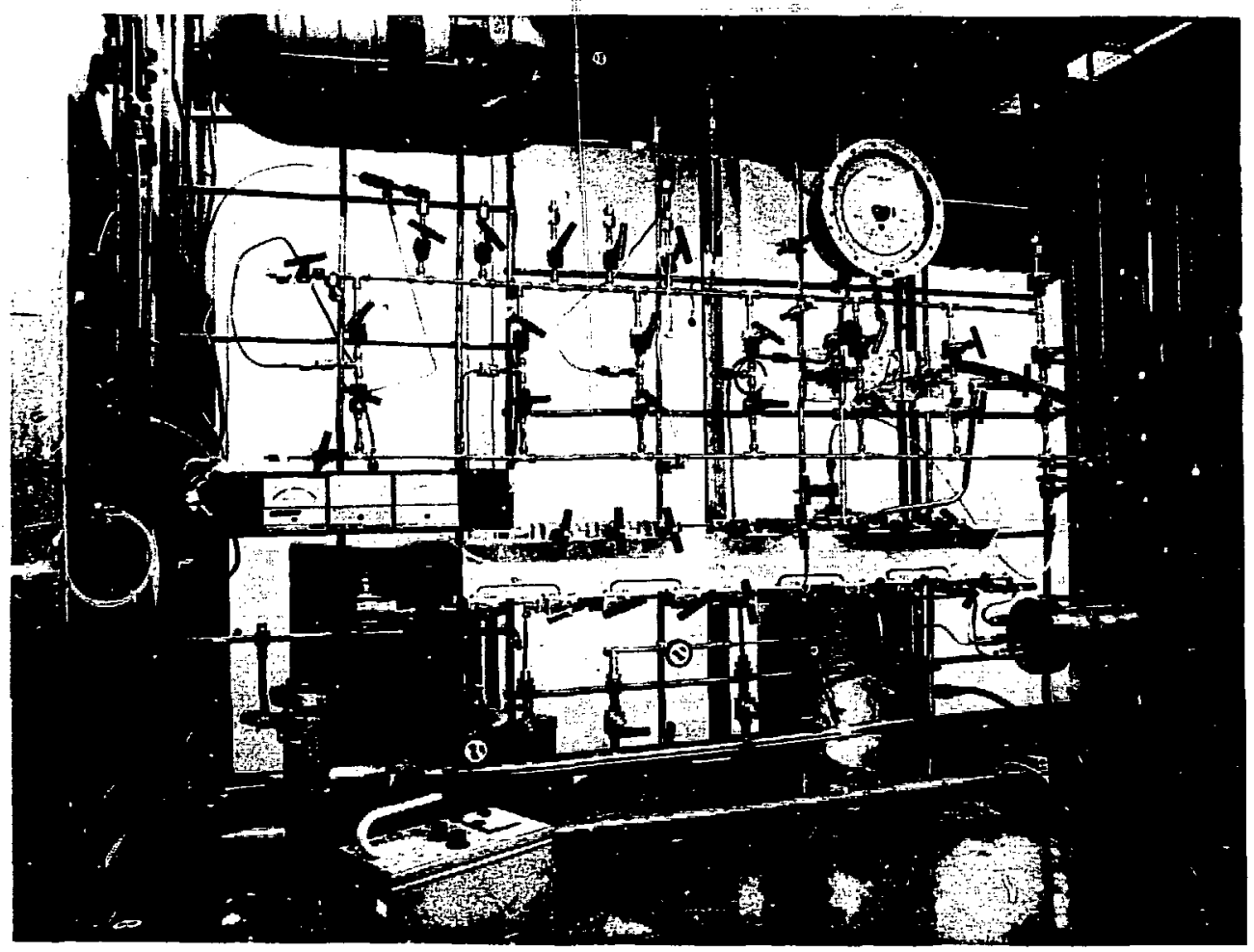

FIG. 3. ${ }^{3} \mathrm{He}$ implanting system. This system consists of a low-pressure circulation and recovery section and a high-pressure section for introducing gases into the reaction chamber. 


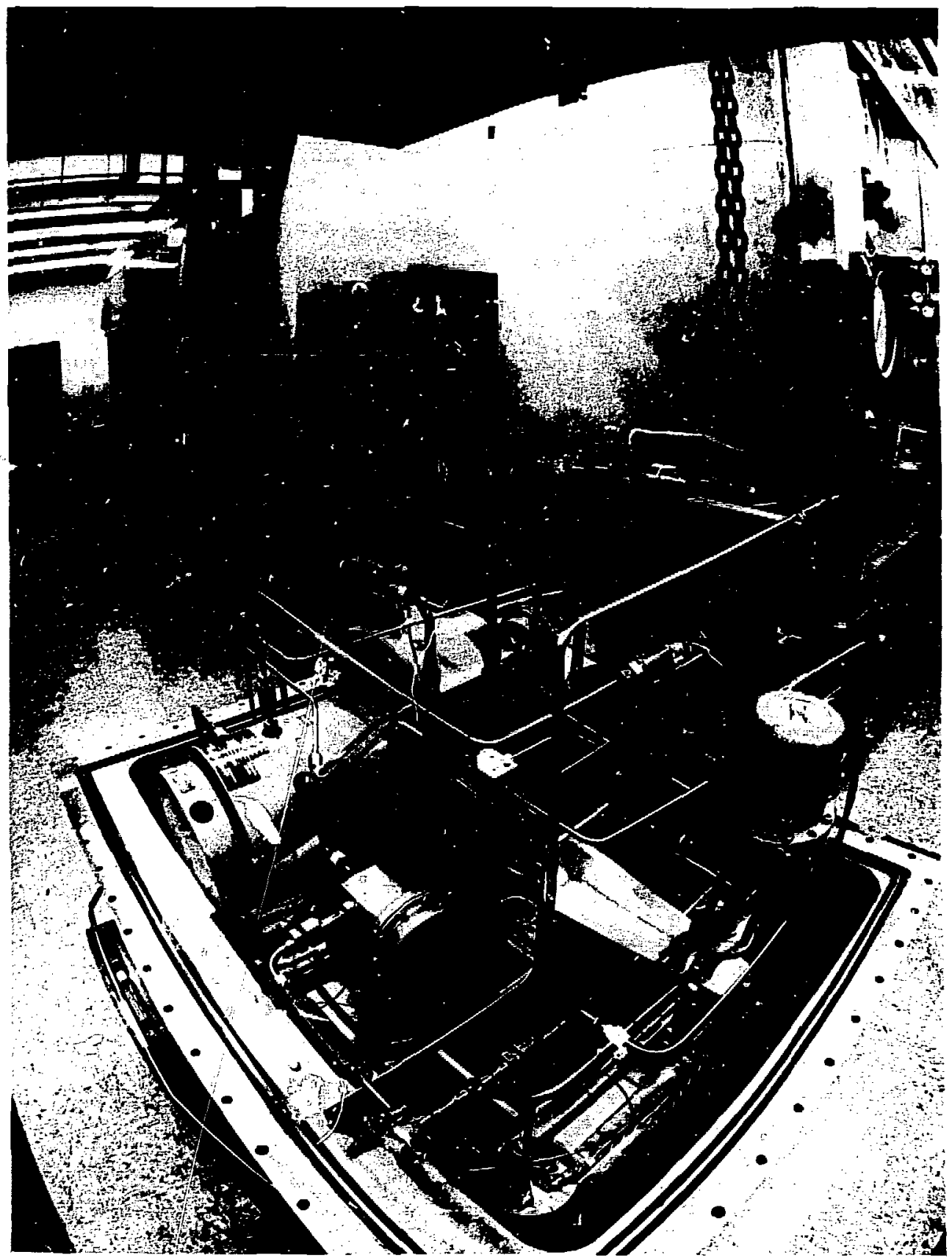

FIG. 4. High-pressure tritium compressor. The compressor was enclosed in a welded heavy-walled steel container because of the compressor's substantial size and weight and large tritium inventory. 
placed inside a secondary container-in this case, a glove box of lightweight construction. If the cell broke, a catalyzer-absorber clean-up system would handle any tritium release. In this instance, the glove box was far more costly than the simple pipe enclosure described in the first example. However, using the glove box is still cost-e[fective because the glove box may be used for future projects once the ir spectrometer is no longer needed.

\section{Laser Fusion Target Loader}

The laser fusion target loader is a good example of a hybrid system (Fig. 5). Glass microsphere targets are loaded by permeation in small beryllium pressure tuoes at about $700 \mathrm{~K}$ at gas densities up to $10 \mathrm{mg} / \mathrm{cm}^{3.8}$ at times, gas pressures approach the yield point of beryllium. (The metal was chosen for its low hydrogen permeation at $700 \mathrm{~K}$, not its strength.) The beryllium pressure tubes are connected to a manifold by mechanical pressure fittings, and the manifold and tubes fit inside a lightweight secondary container; the gas supply sys:am is made of mechanically joined 316 VIM/VAR stainless steel and is a singlecontainment system.

\section{COST-SAVING CONSTRUCTION TECHNIQUES}

\section{Mechanical Joints}

Mechanical joints of the AE Cone type are as safe or safer than welded joints (which decrease the tubing strength at the weld) and are cheaper because radiography and dye-penetration tests are not necessary. The use of fittings can also save engineering and drafting time. Threaded precut 316 stainless

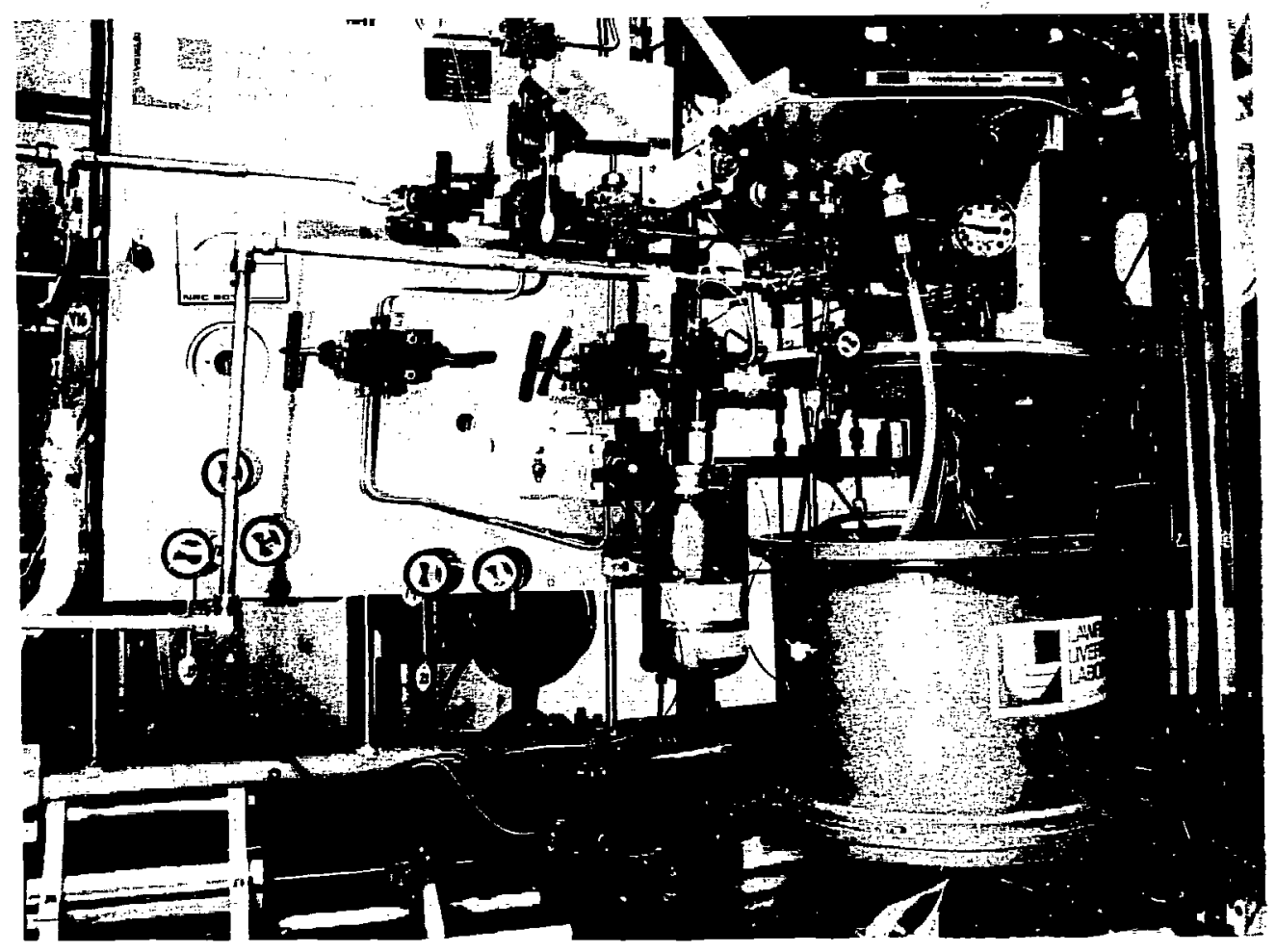

FIG. 5. Laser fusion target loader. This system is a good example of the effective use of both single and douhle containment. The large lightweight secondary container on the right is in the lowered position. 
steel tubing is available in nearly all lengths up to several feet long.

The use of mechanical joints could have offered substantial cost savings during fabrication of the high-pressure pumping system without compromising safety. Because the valve packings are pressurechecked for leaks every time the system is char $_{\varepsilon}$ ed with tritium, the mechanicai joints couid also be checked for leaks with li•lle additional effort.

\section{Welds}

In some cases, welds are more cost-effective than mechanical joints. Generally, the labor cost of installation, the accessibility of thr: joint after assembly, and the nature of the experiment are the most important considerations.

\section{CHOICE OF CONTAINMENT LEVELS}

Choosing the appropriate and cost effective eontainment system requires individual evaluation of each system and subsystem. The foregoing discussion provides exanples of possible solutions for a variety of equipment and circumstances. In the following examples, primary considerations in design were installation vs maintenance costs and hazards to cperating personnel.

To contain a multivalved, high-inventory, high-pressure system used for routine work, we would choose a hybrid containment design. Although total enclosure of the entire apparatus in a glove box might appear reasonable at first, the presence of small amounts of tritium in the secondary container (avoidable only by adding a cap- ture clean-up system and operating it continuously) would limit access during operation and maintenance of the system.

The ultimate fail-safe double-containment system is the stack effluent recovery system, or "stack grabber." A stack grabber represents a onetime investment that continuously covers all systems and offers good protection against human error. A system costing $\$ 700,000$ that protects an inventory of 4 million $\mathrm{Ci}$ costs about $50.175 / \mathrm{Ci}$ - less than Sherwood's \$20/Ci value for individual system containment. To provide one system with a gassalvage system cunforming to QA standards would cos. about $\$ 100,000-1 / 7$ the cost of a stack grabber.

\section{CONCLUSIONS}

A number of steps can be taken to cut the costs of tritium-handling systems without compromising safety. These are:

1. Use the least expensive commercial-grade materials to make secondary systems (e.g., those that serve a bursting disk or back up a weak compo- nent), vacuum lines, and containment structures for areas that contann less than $1000 \mathrm{Ci}$.

2. Use mechanical connections wherever possible.

3. Isolate tritium-handling areas to minimize the extent of containment needed.

4. Use the minimum number of components. 


\section{REFERENCES}

1. A. E. Sherwood, Lawrence Livermore Laboratory, Livermore, Calif., private communication (1968; unpublished report, "Cost Benefit Analysis for Tritium Release").

2. D. W. Alvarez and R. Cornog, "Helium and Hydrogen of Mass 3," Phy.s. Rev. 56,613 (1939).

3. D. G. Jacobs, "Sources of Tritium and Its Behavior upon Release to the Environment," Oak Ridge National Laboratory, Oak Ridge, Tenn., TID 24635 (1968).

4. L. M. Dorfman and B. A. Hemmer, "Ion Pair Yield of Tritium-Oxygen Reactions," J. Chem. Phys. 22, 1555 (1954).

5. R. Z. Morgan, "Radiation Hazards Associated with Tritium," in Seminaire sur la Protection Contre les Dangers du Tritium (Service Central de Protection Contre les Rayonnements Ionizants, le Vesinet, April I6-18, 1964; CONF-654013), pp. I-3.

6. J. 1. Cohne and G. H. Higgins, "The Socioeconomic Impact of Low Level Tritium Releases to the Environment," in Tritium, A. A. Moghissi and M. W. Carter, Eds. (Messenger Graphics, Las Vegas, Nev., 1973).

7. R. T. Tsugawa and P. C. Souers, "A Secondary Containment System for a High Tritium Research Cryostat," in Proc. Intl. Conf. Radiation Effects and Tritium Technology for Fusion Reactors, J. S. Watson and F. W. Wiffen, Eds. (Gatlinburg, Tenn., 1975), CONF-750989 (National Technical Information Service, Springfield, Va., 1976), p. 220.

8. P. C. Souers and R. T. Tsugang, "Manufacture of DT Filled Glass Targets," Rev. Sci. Inst. (6) 46 (1975).

KMG:jm 